\title{
The role of supply chain visibility, supply chain flexibility, supplier development on business performance of logistics companies
}

\author{
Faurani Santi Singagerda ${ }^{a^{*}}$, Achmad Tito Fauzan ${ }^{\mathrm{b}}$ and Andi Desfiandi ${ }^{\mathrm{c}}$
}

${ }^{a}$ Faculty of Economics and Business Institute of Informatics and Business Darmajaya, Lampung, Indonesia

${ }^{b}$ Faculty of Social and Politics, University of Pelita Harapan, Indonesia

${ }^{c}$ Faculty of Economics and Business Darmajaya Institute informatics and Business, Indonesia

\section{A B S T R A C T}

Article history:

Received October 1, 2021

Received in revised format

October 25, 2021

Accepted December 102021

Available online

December 112021

Keywords:

Supply chain visibility

Supply chain flexibility

Supplier development

Business performance

\begin{abstract}
This study aims to determine the effect of supply chain visibility on business performance, to determine the effect of supply chain flexibility on business performance and to determine the effect of supplier development on business performance. The sample of respondents in this study were 120 respondents from logistics companies in Tangerang. Type of research is quantitative research. The data analysis technique used structural equation modeling and SmartPLS for analyzing data. The data collection method in this study was carried out using a survey method, namely by distributing online questionnaires to respondents in the form of questions. The data collection method in this study was an online questionnaire by google form. The sample selection method in this study is simple random sampling. The results of the analysis that have been carried out concluded that Inventory Control, Supply Chain Flexibility, Supply Chain Visibility, Supplier Development had positive and significant influence on business performance.
\end{abstract}

\section{Introduction}

According to Benzidia et al. (2020) The industrial revolution 4.0 has brought several clear and relevant benefits, namely increased flexibility, quality standards, efficiency, and productivity. This will enable mass customization for companies to meet customer demands, create value through the continuous introduction of new products, and market services. Moreover, the collaboration between machines and humans can affect the social life of workers, especially with regard to optimizing decision-making. According to Juwaini et al. (2021) Logistics as a support for industry 4.0 must adapt to or follow progress in these three points. This adaptation is a must to survive and grow in carrying out the logistics function so that it remains an important part of the movement of goods, information, and machines. According to Rudyanto et al. (2021); Juwaini et al. 2021) The fundamental concept explains that Industry 4.0 is still developing towards a more efficient state in terms of costs, time, and labor for production and services. Smooth production no longer relies on supply and distributors, but both are integrated with a strong and efficient logistics system. The role of logistics is an important part of ICT-based Industry 4.0, so the logistics related to it must change to Logistics 4.0. Benzidia et al. (2020) and Delic et al. (2020)) explain that the implications of Industry 4.0 on logistics are very large and important. The demand for individual products and services will continue to increase. Thus, logistics inside and outside the industrial system must adapt to a constantly changing environment. Logistics systems will become increasingly complex so that they cannot be handled with normal planning and control practices.

According to Doetzer et al. (2020) and Dubey et al. (2011), every company will make every effort to increase productivity, efficiency, fast, easy service, and continue to create new innovations to stay ahead and survive in the market. In addition, a 
company must also understand and know what consumers need so that productivity and efficiency can be achieved (Hofman et al., 2020). Supply Chain Risk Management is a risk that occurs in the flow of products, information, and raw materials to the delivery of final products that threatens the entire supply chain from initial suppliers to consumers. There are several problems in logistics companies, namely where inventory control is still not optimal, and the effectiveness of supply chain management is still not effective, so this is an interesting phenomenon to study. PT Sulindo also has a problem if the amount of inventory it keeps is very small. According to Hamadneh et al. (2021) and Hofman et al. (2020) with a good inventory control system, companies can minimize inventory shortages.

Most companies hope they don't have a large stockpile and also do not have to stockpile too much. The supply of feed and vitamins fluctuates and tends to decrease, indicating that the control of feed and vitamin supplies is not optimal. This research has a focus on B2B because customers are logistics companies because logistics companies have wholesale consumers or agents and not end consumers. Another problem faced by logistics companies is that most of their supply chain management is still in the old-fashioned way, because the top management currently serving are people whose thinking is not advanced or still likes conventional methods and so far there has been no socialization and employee participation to management. peaks and lack of smooth communication about the supply chain so that it makes the problem of risk management culture in this company interesting and interesting to study. The supply decision is still unilateral from the top management, and there is no delegation of authority. Logistics companies also sometimes experience problems such as the size or size of the shrimp does not meet the minimum size of the distributor's request so that there are some distributors who stop to take shrimp from the logistics company. In addition, sometimes logistics companies are also less careful in quality control of their orders to the distributors so that the quantity ordered does not match. This means that sometimes the amount sent is less than the amount ordered. Sometimes the shrimp delivered exceeds the number of orders.

Based on the description of the problem above, it can be seen that logistics companies have problems with their supply chain management. According to Doetzer et al. (2020) and Dubey et al. (2011), supply chain management has evolved from manual optimization, logistics and mechanization focusing on modern, digital and automated integration and coordination of all supply chain elements. It plays an important role in tackling the increasingly complex global supply chain today. Primarily, in facilitating and optimizing the flow of products, information, and finance, enabling companies to create better value relationships and improve overall business efficiency. According to Hofman et al. (2020) Supply Chain Management will not be successfully implemented if it is not linked to performance measurement. Performance measurement or performance is very important for successful supply chain management. Ineffective performance measures will never reveal what adjustments are needed in the supply chain. Performance improvement, effective collaboration with suppliers and customers to streamline the supply chain is an interactive process. This means that how performance measurement is carried out is very important and is a continuous process. Building and maintaining buyer-supplier relationships in supply chain management is the basis of Sustainable Competitive Advantage and is also supported by supply management skills which include: (a) strengthening close working relationships with a limited number of suppliers, (b) promoting open relationships between supply- chain partners, (c) develop a long-term strategic orientation to achieve mutual benefits.

The research replicates the research of Ibrahim et al. (2010) and Masudin et al. (2021), which explores the relationship between vulnerability mitigation strategies and supply chain effectiveness with security culture as a moderator by changing the object of research. Operations managers are responsible for decisions that bind the transformation system. This decision framework says that operations have 5 (five) main decision responsibilities which are as follows: 1. Process 2 . Capacity 3. Supply chain management 4. Manpower 5. Quality (quality). Praharsi et al. (2015) and Rudyanto et al. (2021) stated that inventory or inventory is a term used to show everything or resources that are stored in anticipation of meeting the emergence of demand. For companies engaged in trading or trading companies record inventory as merchandise inventory, inventory here is goods purchased by companies with the aim of being resold in their normal business without going through changes in shape and quality. Indicators of inventory control are: 1 . Provide permanent and visible storage for material supply 2 . Set threshold for each type of material that refers to production fluctuations 3. Inventory position is always monitored. Ibrahim et al. (2010) and Masudin et al. (2021) define Supply Chain Management as a network of suppliers, manufacturing, assembly, distribution, and logistics facilities that form the purchasing function of materials, the transformation of materials into semifinished goods and finished products, and the distribution process of products. it to consumers. Supply chain visibility is needed in managing upstream and downstream relationships to increase product value in the market at less overall cost. Indicators of supply chain visibility are: 1 . Inform ahead of changes in requirements 2 . Knowledge sharing about core business processes 3 . Inform each other about future customer needs 4 . Increase integration of activities across the supply chain 5. Collaborate to monitor product movement Supply chain flexibility is a strategic initiative that enables companies to respond quickly to changes in the market, including unexpected actual disruptions in the supply chain. This study aims to determine the effect of supply chain visibility on business performance, to determine the effect of supply chain flexibility on business performance and to determine the effect of supplier development on business performance.

Supply chain visibility is needed in managing upstream and downstream relationships to increase product value in the market at less overall cost. Indicators of supply chain visibility According to Benzidia et al. (2020), Delic et al. (2020) and Purwanto et al. (2021) there are: 1. Inform before changing needs 2. Share knowledge about core business processes 3 . Inform each 
other about future needs of customers 4. Increase the integration of activities across the supply chain 5. Collaborate to monitor product movement. Supply chain flexibility is a strategic initiative that enables a company to respond quickly to changes in the market, including unexpected actual disruptions in the supply chain.

Supply chain flexibility is the source of maintaining sustainable performance in anticipating changes in customer requirements. Benzidia et al. (2020), Delic et al. (2020) and Purwanto et al. (2021) conclude that flexibility is a necessary capability that helps companies improve their performance, retain resources and manage markets. Indicators of supply chain flexibility are: 1. Can shift purchases of goods from one supplier to another 2. Can change the number of supplier orders 3 . Various means of transportation are available in delivering products to customers 4 . Sufficient production capacity to accommodate increased demand.

Supplier development is an effort to improve performance and ability to meet the organization's current and future needs. Prahiawan et al. (2022) emphasize that outsourcing activities enable organizations to manage labor and manufacturing more effectively to reduce overall production costs. Indicators of supplier development are: (Purwanto et al., 2021) 1. Using multiple suppliers for purchased goods to create competitive pressure 2. Considerations for improving future business relationships 3. Assessing supplier performance through a formal supplier evaluation system 4 . Development targeted quality and other measures of improvement within suppliers Supply chain effectiveness represents the direct and indirect effects of adopting a mitigation strategy. Linking mitigation strategies with supply chain effectiveness is an important measure related to supply chain performance.

\section{Hypothesis Development}

\subsection{The relationship between supply chain visibility and business performance}

The implementation of supply chain visibility has a positive impact on increasing business performance, this is in accordance with research by Praharsi et al. (2015); Prahiawan et al. (2022) that there is a positive influence between supply chain visibility and business performance, another study by Bagchi et al. (2005); Benzidia et al. (2020) gave the same result, namely that there was a positive influence between supply chain visibility and business performance, this is in line with Hamadneh et al. (2021); Hofman et al. (2020); Ibrahim et al. (2010) that there is a positive influence between supply chain visibility and business performance. Based on previous research studies and the above theory, the following hypothesis is formulated:

Hypothesis 1: There is a positive influence between supply chain visibility and business performance.

\subsection{The relationship between supply chain flexibility and business performance}

The application of supply chain flexibility has a positive impact on increasing business performance, which is in accordance with research by Praharsi et al. (2015) and Prahiawan et al. (2022) that there is a positive relationship between supply chain flexibility and business performance, another study by Hamadneh et al. (2021) and Hofman et al. (2020) gave the same result, namely that there was a positive influence between supply chain flexibility and business performance, which is in line with Bagchi et al. (2005); Benzidia et al. (2020); Delic et al. (2020) that there is a positive influence between supply chain flexibility and business performance. Based on previous research studies and the above theory, the following hypothesis is formulated:

Hypothesis 2: There is a positive effect between supply chain flexibility and business performance.

\subsection{Relationship between supplier development and business performance}

The implementation of supplier development has a positive impact on increasing business performance, which is in accordance with research by Hofman et al. (2020), Ibrahim et al. (2010) and Masudin et al. (2021) that there is a positive influence between supplier development and business performance, another study by Praharsi et al. (2015) and Prahiawan et al. (2022) gave the same result, namely that there is a positive influence between supplier development and business performance, this is in line with Doetzer et al. (2020), Dubey et al. (2011), Hamadneh et al. (2021), Hofman et al. (2020) and Ibrahim et al. (2010) that there is a positive influence between supplier development and business performance. Based on previous research studies and the above theory, the following hypothesis is formulated:

Hypothesis 3: There is a positive influence between supplier development and business performance.

The hypothesis that will be proven in this study, namely:

$\mathbf{H}_{1}$ : There is an effect of supply chain visibility on business performance.

$\mathbf{H}_{2}$ : There is an effect of supply chain flexibility on business performance.

$\mathbf{H}_{3}$ : There is an effect of supplier development on business performance. 


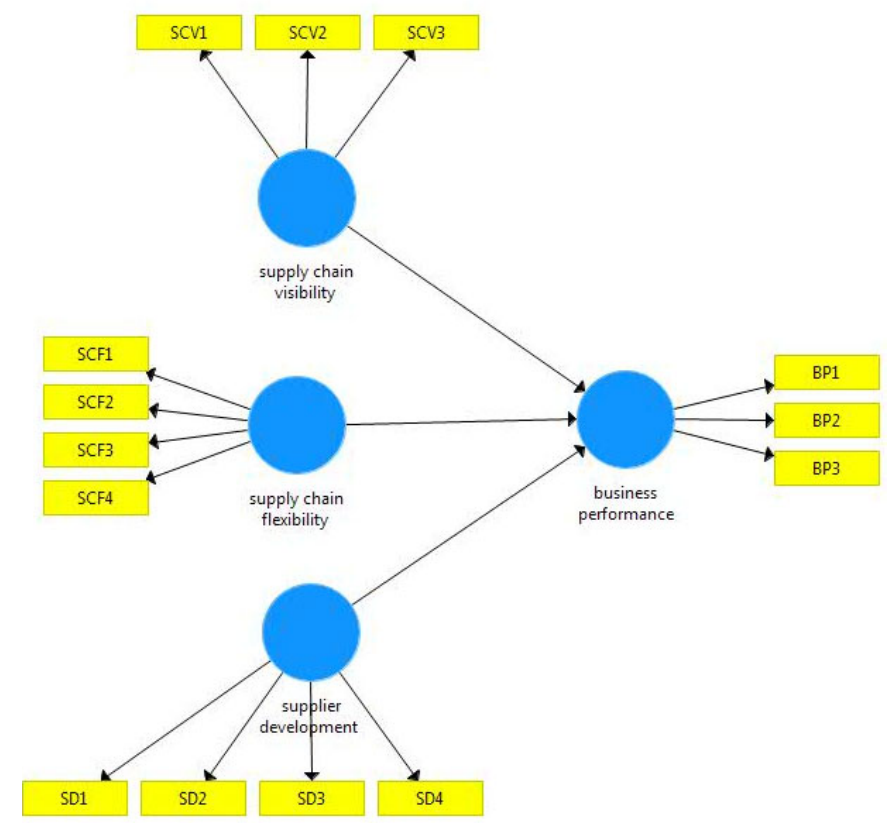

\section{Method}

Fig. 1. Research Model

Type of Research This research is a type of quantitative research. Quantitative research method is one type of research whose specifications are systematic, well-planned, and clearly structured from the beginning to the making of the research design. Another definition states that quantitative research is research that demands the use of numbers, starting from data collection, interpretation of the data, and the appearance of the results. Similarly, at the conclusion of the research, it would be better if it was accompanied by pictures, tables, graphs, or other displays (Purwanto et al., 2021). Population and Sample The population in this study is a logistics company. The sample is part of the population. The sampling technique in this research is simple random sampling. The sample in this study amounted to 120 respondents. As an alternative to CBSEM, the component-based approach with Partial Least Square (PLS) analysis orientation shifts from testing causality/theory models to component based predictive models. PLS can analyze as well as latent variables formed by reflective indicators and formative indicators. The sample size in PLS is determined by one of the following rules (Purwanto et al., 2021). The steps for the Partial Least Square (PLS) method carried out in this study are as follows: (1) Designing a Measurement Model The measurement model (outer model) is a model that connects latent variables with manifest variables. (2) Designing a Structural Model Structural model. (3) Building a Path Diagram of the relationship between variables on a flow chart that can specifically help in describing a series of causal relationships between constructs from the theoretical model that has been built in the first stage. (4) Elaborating the Flowchart into Equation.

\section{Result and Discussion}

\subsection{Evaluation of Measurement Model (Outer Model)}

Convergent Validity testing for reflective indicators can be done by using the correlation between the indicator scores and their construct scores. Measurements with reflective indicators show that there is a change in an indicator in a construct when other indicators in the same construct change. The following are the results of calculations using the smart PLS 3.0 computer program:

Table 1

Reliability Testing Result

\begin{tabular}{|c|c|c|c|}
\hline Variables & Cronbach's Alpha & Composite Reliability & AVE \\
\hline supply chain visibility & 0.976 & 0.984 & 0.954 \\
\hline supply chain flexibility & 0.994 & 0.993 & 0.973 \\
\hline supplier development & 0.926 & 0.936 & 0.746 \\
\hline business performance & 0.994 & 0.996 & 0.985 \\
\hline
\end{tabular}

According to Purwanto et al. (2021) a latent variable can be said to have good reliability if the composite reliability value is greater than 0.7 and Cronbach's alpha value is greater than 0.7 . 


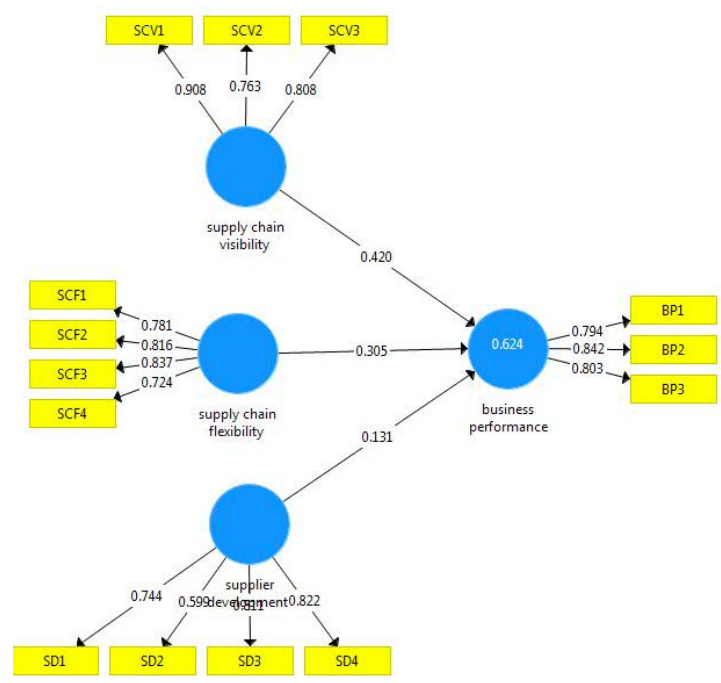

Fig. 2. Convergent Validity

\subsection{Structural model (inner model)}

Evaluation of the Structural Model (Inner Model) Evaluation of the structural model on SEM with PLS is done by performing the R-squared $\left(\mathrm{R}^{2}\right)$ test and the significance test through the estimation of the path coefficient. The value of $\mathrm{R}$-squared $\left(\mathrm{R}^{2}\right)$ is used to measure how much influence certain independent latent variables have on the dependent latent variable. According to Purwanto et al. (2020) the $\mathrm{R}^{2}$ result of 0.67 indicates that the model is categorized as good. The results of the analysis show the R2 value of this study is 0.6724 , which means it has a value greater than 0.67 . So, it can be said that the model formed is categorized as a good model. Testing $\mathrm{R}^{2}$ the output for the value of $\mathrm{R}^{2}$ using the SmartPLS 3.0 computer program is obtained:

\section{Table 2}

R-Square adjusted

\begin{tabular}{ll}
\hline Variables & R-square adjusted \\
\hline Business Performance & 0.624 \\
\hline
\end{tabular}

In Table 3 it can be explained that the adjusted $\mathrm{R}^{2}$ value of the supply chain visibility, supply chain flexibility and supplier development variables on the dependent variable Business Performance is 0.624 . This value is categorized as strong. supply chain visibility, supply chain flexibility and supplier development variables contributed to the dependent variable business performance by $62.4 \%$ while the remaining $37.6 \%$ was influenced by other variables not discussed in this study.

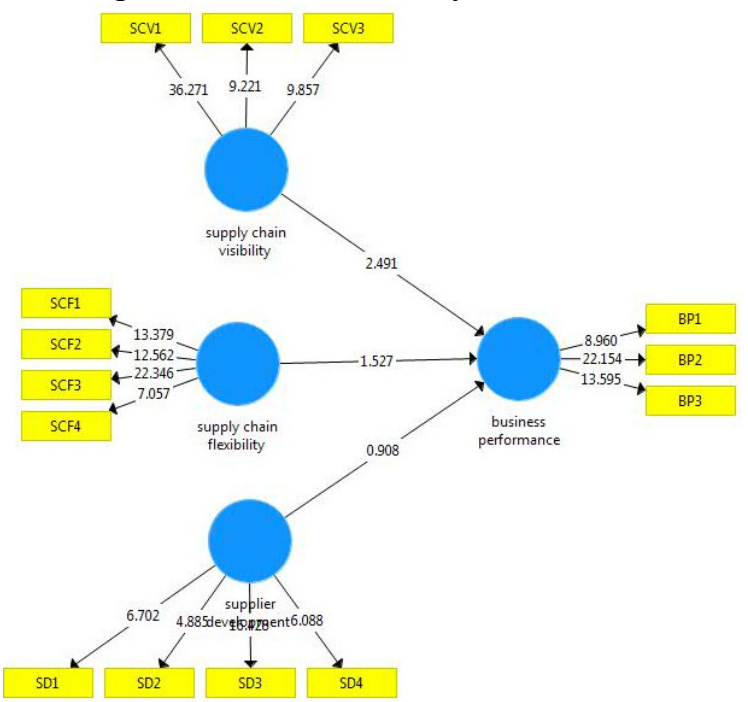

Fig. 3. Hypotheses Testing 
Significance Test The significance test on the SEM model with PLS aims to determine the effect of exogenous variables on endogenous variables. The hypothesis is said to be significant if it has a probability value ( $\mathrm{p}$-value) $<5 \%$.

\section{Table 4}

Hypotheses Testing for Direct Effect

\begin{tabular}{lll}
\hline Hypotheses & P - Value & \\
\hline Supply chain visibility $\rightarrow$ business performance & 0.001 & Result \\
Supply chain flexibility $\rightarrow$ business performance & 0.001 & Significant \\
Supplier development $\rightarrow$ business performance & 0.000 & Significant \\
\hline
\end{tabular}

\subsection{The relationship between supply chain visibility and business performance}

The results of data analysis using SmartPLS yields a p-value of $0.001<0.050$ and it is concluded that supply chain visibility has a significant effect on business performance, an increase in supply chain visibility variable will have a significant effect on increasing business performance variable and decreasing Company Ability variable will have a significant effect on decreasing business performance. These results are in line with the research conducted by Doetzer et al. (2020), Dubey et al. (2011), Hamadneh et al. (2021) and Hofman et al. (2020) that supply chain visibility has a positive and significant effect on business performance.

\subsection{The relationship between supply chain flexibility and business performance}

The results of data analysis using SmartPLS provides a p-value of $0.001<0.050$ and it is concluded that supply chain flexibility has a positive and significant effect on business performance, an increase in supply chain flexibility variable will have a significant effect on increasing business performance variable and decreasing supply chain flexibility variable will have a significant effect on decreasing business performance. These results are in line with the research conducted by Ibrahim et al. (2010), Masudin et al. (2021), Praharsi et al. (2015) and Rudyanto et al. (2021) that supply chain flexibility has a positive and significant effect on business performance.

\subsection{The relationship between supplier development and business performance}

The results of data analysis using SmartPLS gives a p-value of $0.000<0.050$ and it is concluded that supplier development has a positive and significant effect on business performance, an increase in supplier development variable will have a significant effect on increasing business performance variable and decreasing supplier development variable will have a significant effect on decreasing business performance. These results are in line with the research conducted by Purwani et al. (2016), Redjeki et al. (2020), Susanty et al. (2018) and Yang et al. (2021) that supplier development has a positive and significant effect on business performance

\section{Practical Implications}

To improve the performance of logistics companies, it can be done by increasing the supply chain visibility variable by increasing the indicators, increasing the supply chain visibility variable will encourage a significant increase in logistics company performance. To improve the performance of logistics companies, it can be done by increasing the supply chain flexibility variable by increasing its indicators, increasing the supply chain flexibility variable will encourage a significant increase in logistics company performance and increasing logistics company performance by encouraging an increase in the variables and indicators of supplier development.

\section{Theoretical Implications}

Supply chain visibility has a significant effect on business performance, an increase in supply chain visibility variable will have a significant effect on increasing business performance variable and decreasing Company Ability variable will have a significant effect on decreasing business performance. These results are in line with the research conducted by Doetzer et al. (2020), Dubey et al. (2011), Hamadneh et al. (2021) and Hofman et al. (2020). Supply chain flexibility has a significant effect on business performance. These results are also in line with the research conducted by Ibrahim et al. (2010), Masudin et al. (2021), Praharsi et al. (2015) and Rudyanto et al. (2021) and supplier development has a significant effect on business performance. These results are in line with the research conducted by Purwani et al. (2016), Redjeki et al. (2020), Susanty et al. (2018) and Yang et al. (2021).

\section{Conclusion}

The results of the analysis that has been carried out conclude that Supply Chain Flexibility has a significant effect on business performance. Supply Chain Visibility has a significant effect on business performance, Supplier Development has a significant effect on business performance. The results of the research that has been carried out; researchers can provide 
suggestions for further researchers. It is hoped that they can continue research on Supply Chain Effectiveness with other variables outside of the variables that have been studied to find out what factors can affect business performance. Expected to continue research on Supply Chain Effectiveness with variables other variables outside the variables that have been studied to find out what factors can influence Supply Chain performance.

\section{References}

Bagchi, P.K., \& Chun, H.B. (2005). Supply Chain Integration: a European survey. The International Journal of Logistics Management, 16(2), 275-294.

Benzidia, S., \& Makaoui, N. (2020, July). Improving SMEs performance through supply chain flexibility and market agility: IT orchestration perspective. In Supply Chain Forum: An International Journal, 21(3), 173-184.

Delic, M., \& Eyers, D. R. (2020). The effect of additive manufacturing adoption on supply chain flexibility and performance: An empirical analysis from the automotive industry. International Journal of Production Economics, $228,107689$.

Doetzer, M. (2020). The role of national culture on supply chain visibility: Lessons from Germany, Japan, and the USA. International Journal of Production Economics, 230, 107829.

Dubey, R., \& Chakrabarty, A. (2011). Role of innovative supply chain practices and total quality management (TQM) on performance of Indian cement manufacturing firms: an empirical study. Polish journal of management studies, 4, 96-119.

Hamadneh, S., Pedersen, O., \& Al Kurdi, B. (2021). An Investigation of The Role of Supply Chain Visibility into The Scottish Blood Supply Chain. Journal of Legal, Ethical and Regulatory Issues, 24, 1-13.

Hofman, W. J. (2020). Supply chain visibility ledger. In Blockchain and Distributed Ledger Technology Use Cases (pp. 305329). Springer, Cham.

Ibrahim, H. W., \& Zailani, S. (2010). A review on the competitiveness of global supply chain in a coffee industry in Indonesia. International Business Management, 4(3), 105-115.

Masudin, I., Ramadhani, A., Restuputri, D. P., \& Amallynda, I. (2021). The effect of traceability system and managerial initiative on indonesian food cold chain performance: A Covid-19 pandemic perspective. Global Journal of Flexible Systems Management, 22(4), 331-356.

Praharsi, Y., \& Purnomo, H. D. (2015). Designing e-supply chain collaborative management: A case study in total food solution company. Jurnal Ilmiah Teknik Industri, 2(3).

Prahiawan, W., Fahlevi, M., Juliana, J., Purba, J., Khamaludind, K., Syam, S., \& Lestari, S. (2022). The effect of supply chain quality perception and country of origin on Smartphones purchase intention of Indonesian consumers. Uncertain Supply Chain Management, 10(1), 277-284.

Purwani, T., \& Nurcholis, L. (2016). Supply Chain Performance Improvement Strategy through Quality of Synergy in the Automotive Components Industry. JDM (Jurnal Dinamika Manajemen), 7(1), 32-44.

Purwanto, A., \& Juliana (2021). The effect of supplier performance and transformational supply chain leadership style on supply chain performance in manufacturing companies. Uncertain Supply Chain Management, 10(2), 1-8.

Purwanto, A., Asbari, M., Santoso, T. I., Paramarta, V., \& Sunarsi, D. (2020). Social and Management Research Quantitative Analysis for Medium Sample: Comparing of Lisrel, Tetrad, GSCA, Amos, SmartPLS, WarpPLS, and SPSS. Jurnal Ilmiah Ilmu Administrasi Publik, 10(2), 518-532.

Redjeki, F., Effendi, A. D., Novari, E., Mubarok, M., \& Suparman, N. (2020). Weaving Small Industry Management Strategy through an Integrative Supply Chain Approach. Journal of Advanced Research in Dynamical \& Control Systems, 12(20), 2582-2587.

Rudyanto, R., Pramono, R., \& Purwanto, A. (2021). The influence of antecedents of supply chain integration on company performance. Bagchi, $P K \&$ Chun HB (2005). Supply Chain Integration: a European survey. The International Journal of Logistics Management, 16(2), 275-294.

Susanty, A., Sirait, N. M., \& Bakhtiar, A. (2018). The relationship between information sharing, informal contracts and trust on performance of supply chain management in the SMEs of batik. Measuring Business Excellence.

Yang, J., Xie, H., Yu, G., \& Liu, M. (2021). Antecedents and consequences of supply chain risk management capabilities: An investigation in the post-coronavirus crisis. International Journal of Production Research, 59(5), 1573-1585. 
(C) 2022 by the authors; licensee Growing Science, Canada. This is an open access article distributed under the terms and conditions of the Creative Commons Attribution (CC-BY) license (http://creativecommons.org/licenses/by/4.0/). 